\title{
Mechanism of Oxidative Activation of Fluorinated Aromatic Compounds by NBridged DiironPhthalocyanine. What determines the reactivity?
}

DOI:

10.1002/chem.201902934

\section{Document Version}

Accepted author manuscript

Link to publication record in Manchester Research Explorer

Citation for published version (APA):

De Visser, S., Tobing, A., Mukherjee, G., Colomban, C., Sastri, C., \& Sorokin, A. (2019). Mechanism of Oxidative Activation of Fluorinated Aromatic Compounds by NBridged DiironPhthalocyanine. What determines the reactivity? Chemistry - A European Journal. https://doi.org/10.1002/chem.201902934

Published in:

Chemistry - A European Journal

\section{Citing this paper}

Please note that where the full-text provided on Manchester Research Explorer is the Author Accepted Manuscript or Proof version this may differ from the final Published version. If citing, it is advised that you check and use the publisher's definitive version.

\section{General rights}

Copyright and moral rights for the publications made accessible in the Research Explorer are retained by the authors and/or other copyright owners and it is a condition of accessing publications that users recognise and abide by the legal requirements associated with these rights.

\section{Takedown policy}

If you believe that this document breaches copyright please refer to the University of Manchester's Takedown Procedures [http://man.ac.uk/04Y6Bo] or contact uml.scholarlycommunications@manchester.ac.uk providing relevant details, so we can investigate your claim.

\section{OPEN ACCESS}




\title{
Mechanism of Oxidative Activation of Fluorinated Aromatic Compounds by N-Bridged Diiron-Phthalocyanine. What determines the reactivity?
}

\author{
Cédric Colomban, ${ }^{[\mathrm{a}]}$ Anthonio H. Tobing ${ }^{[\mathrm{b}]}$ Gourab Mukherjee,${ }^{[\mathrm{b}, \mathrm{c}]}$ Chivukula V. Sastri, ${ }^{[\mathrm{c}]}$ Alexander B. \\ Sorokin, ${ }^{*[d]}$ and Sam P. de Visser* ${ }^{*[a]}$
}

\begin{abstract}
The biodegradation of compounds with $\mathrm{C}-\mathrm{F}$ bonds is challenging due to the fact that these bonds are stronger than the $\mathrm{C}$ $\mathrm{H}$ bond in methane. Herein, we present results on the unprecedented reactivity of a biomimetic model complex that contains an $\mathrm{N}$-bridged diiron-phthalocyanine and show it to react with perfluorinated arenes under addition of $\mathrm{H}_{2} \mathrm{O}_{2}$ effectively. To get mechanistic insight into this unusual reactivity, detailed density functional theory calculations on the mechanism of $\mathrm{C}_{6} \mathrm{~F}_{6}$ activation by an iron(IV)-oxo active species of the $\mathrm{N}$-bridged diiron phthalocyanine system were performed. Our studies show that the reaction proceeds through a rate-determining electrophilic $\mathrm{C}-\mathrm{O}$ addition reaction followed by a 1,2-fluoride shift to give the ketone product that can further rearrange to the phenol. A thermochemical analysis shows that the weakest $\mathrm{C}-\mathrm{F}$ bond is the aliphatic $\mathrm{C}-\mathrm{F}$ bond in the ketone intermediate. We demonstrate that the oxidative defluorination of perfluoroaromatics proceeds via a completely different mechanism compared to that of aromatic $\mathrm{C}-\mathrm{H}$ hydroxylation by iron(IV)-oxo intermediates such as cytochrome P450 Compound I.
\end{abstract}

\section{Introduction}

One of the strongest chemical bonds in nature is the $\mathrm{C}-\mathrm{F}$ bond, which arises due to the large difference in electronegativity (EN) between carbon and fluorine (EN = 2.5 vs 4.0). ${ }^{[1]}$ The strength of these $\mathrm{C}-\mathrm{F}$ bonds means they are generally inert in nature and are very difficult to break. For instance, the extensively used polyfluorinated compound Teflon or polytetrafluoroethylene is a highly robust synthetic polymer with strong thermal and chemical resistance. ${ }^{[2]}$ Consequently, molecules with multiple C-F bonds are highly stable and inert, which makes them highly desirable as insulators. ${ }^{[3]}$ Fluorinated compounds find increasing use in many areas, for instance, $40 \%$ of agrochemicals and $25 \%$ of pharmaceuticals currently used contain $\mathrm{C}-\mathrm{F}$ bonds. Their

[a] Dr. C. Colomban, Dr. A. B. Sorokin Institut de Recherches sur la Catalyse et l'Environnement de Lyon, IRCELYON, UMR 5256, CNRS Université Lyon 1 , 2 av. Albert Einstein, 69626 Villeurbanne Cedex, France E-mail: alexander.sorokin@ircelyon.univ-lyon1.fr

[b] Mr. A. H. Tobing, Dr. S. P. de Visser

The Manchester Institute of Biotechnology and School of Chemical Engineering and Analytical Science, The University of Manchester 131 Princess Street, Manchester M1 7DN, United Kingdom E-mail: sam.devisser@manchester.ac.uk

[c] Mr. G. Mukherjee, Dr. Chivukula V. Sastri Department of Chemistry Indian Institute of Technology Guwahati Guwahati-781039, Assam, India E-mail: sastricv@iitg.ac.in

Supporting information for this article is given via a link at the end of the document exceptional stability; however, creates a major environmental burden to society, as natural biodegradation of these compounds is very limited. Consequently, there is major scientific research on going into the activation and degradation of fluorinated compounds considered as emerging pollutants. Due to its small size (van der Waals radius of $1.47 \AA$ ) as well as its low atomic polarizability volume, fluorine is a suitable replacement of hydrogen in molecular design and as such has been inserted into a large variety of organic molecules. ${ }^{[4]}$ The activation of a $\mathrm{C}-\mathrm{F}$ bond requires the breaking of a bond with a strength of about $130 \mathrm{kcal} \mathrm{mol}^{-1}$, which is challenging in chemical catalysis. ${ }^{[5]}$ These bonds are thermally, photochemically, electrooxidatively and often chemically stable; hence are difficult to break. To activate these $\mathrm{C}-\mathrm{F}$ bonds, one needs the use of an electron-rich species, e.g., an electron-rich transition metal complex, a strong reductant or nucleophile, are usually applied. ${ }^{[5]}$ Similarly to the activation of $\mathrm{C}-\mathrm{H}$ bonds, organometallic activation of $\mathrm{C}-\mathrm{F}$ bonds has been the subject of extensive research. ${ }^{[5 d]}$ Alternatively, the $\mathrm{C}-\mathrm{H}$ bonds can be transformed by oxidative pathways. By contrast to the extensive research on $\mathrm{C}-\mathrm{H}$ bond oxidation reactions done over the past century, very few studies have reported $\mathrm{C}-\mathrm{F}$ bond activation under oxidative conditions. The latter reactivity represents a particular case because strong oxidants, which are electrondeficient species, should be involved in the reaction with $\mathrm{C}-\mathrm{F}$ bonds formed by the most electronegative element. Consequently, there are major gaps in our understanding of the mechanism and driving forces of these reactions.

Nature employs a variety of iron-containing enzymes for the selective oxidation of strong $\mathrm{C}-\mathrm{H}$ bonds. In particular, the cytochromes $\mathrm{P} 450$ are heme monooxygenases that form a highvalent iron(IV)-oxo heme cation radical known as Compound I in their catalytic cycle. ${ }^{[6]}$ Compound I reacts with substrates through hydrogen atom abstraction of aliphatic $\mathrm{C}-\mathrm{H}$ bonds, but also can activate $\mathrm{C}=\mathrm{C}$ double bonds, arenes and sulfides. ${ }^{[7]}$ Interestingly, P450 Compound I (Cpd I) is unable to react with methane although there is evidence of ethane and propane oxidation. ${ }^{[8]}$ Clearly, P450 Cpd I cannot cleave the methane $\mathrm{C}-\mathrm{H}$ bond of $105 \mathrm{kcal} \mathrm{mol}^{-1}$ and, therefore, is not expected to be able to activate even stronger bonds, such as the $\mathrm{C}-\mathrm{F}$ bonds in perfluoroarenes by an oxidative pathway.

Although several studies on $\mathrm{C}-\mathrm{F}$ bond oxygenation reactions by iron(IV)-oxo species have been reported, ${ }^{[9]}$ actually little is known on the defluorination of poly- or perfluoro aromatic compounds. Some of us recently reported an excellent defluorination oxidant for poly- and perfluoro aromatic compounds, namely a $\mu$-nitrido diiron phthalocyanine $(\mathrm{Pc})$ complex $\left(\mathrm{tBu}_{4} \mathrm{PcFe}\right)_{2} \mathrm{~N}(\mathbf{1})$, Scheme $1 .{ }^{[10]} \mathrm{A}$ range of aromatic compounds with fluoride substituents (SubF) were investigated with widely ranging yields and turnover numbers (TON). Complex 1 is shown to be able to activate and hydroxylate strong aromatic $\mathrm{C}-\mathrm{F}$ bonds under oxidation conditions 
efficiently; hence 1 appears to be a more powerful oxidant than P450 Cpd I. The question, therefore, is how that is possible and what makes it so efficient. Therefore, we decided to pursue a detailed mechanistic study using experimental and computational techniques. Our study proposes a novel mechanism for aromatic hydroxylation of fluorinated arenes that is completely different from that of non-fluorinated arenes. In particular, the reaction takes place through the initial formation of a ketone. In the ketone structure an aliphatic $\mathrm{C}-\mathrm{F}$ bond is broken in the re-aromatization step to give the fluorinated phenols.

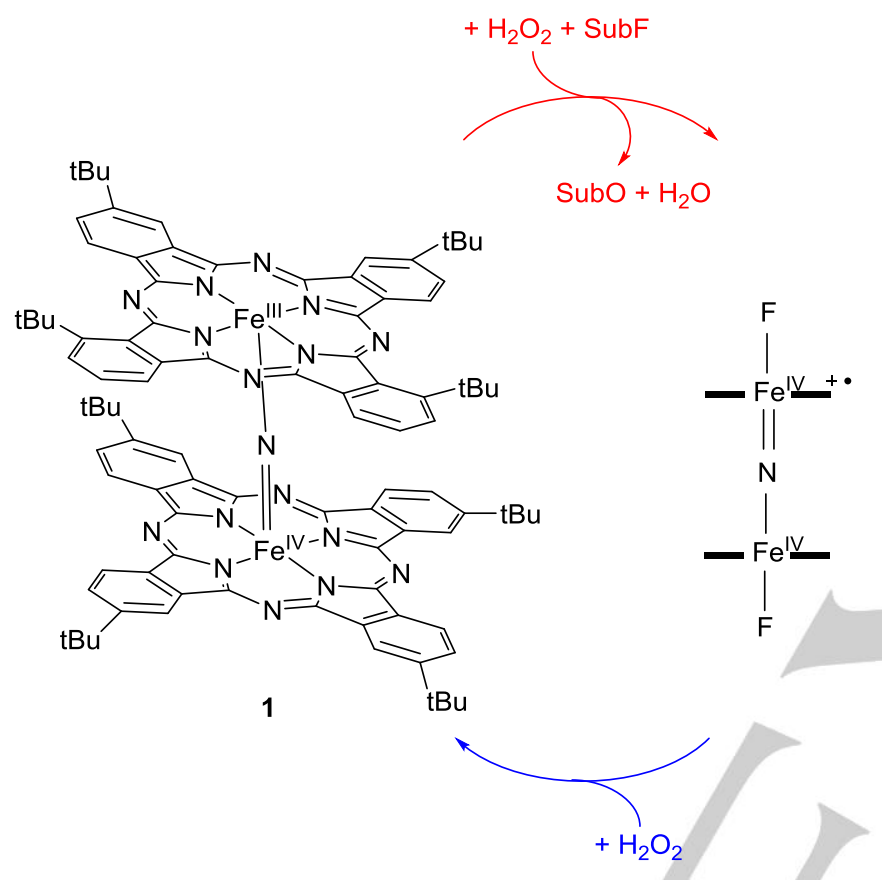

Scheme 1. Oxidant and reaction cycle with fluorinated substrate (SubF) studied.

\section{Results}

A combination of experimental and computational studies was performed on the activation of polyfluorinated arenes, namely $\mathrm{C}_{6} \mathrm{~F}_{5} \mathrm{Y}\left(\mathrm{Y}=\mathrm{F}, \mathrm{NO}_{2}, \mathrm{CN}, \mathrm{CF}_{3}\right)$ with the $\mu$-nitrido diironphthalocyanine complex $\left(\mathrm{tBu}_{4} \mathrm{PcFe}\right)_{2} \mathrm{~N}$ (1) as described in Scheme 1 . The high reactivity of $\mathbf{1}$ is associated with the formation of high-valent diiron-oxo species. These species supported by phthalocyanine, porphyrin and porphyrazine ligands have been characterized by spectroscopic methods and DFT calculations. ${ }^{[10 b, 10 c, 11]}$ Particular focus of the work is on establishing the reaction mechanism and the origin of $\mathrm{C}-\mathrm{F}$ bond cleavage in the reaction.

\section{Experimental reactivity study}

To determine the regioselectivity of the initial reaction step involving the diiron-oxo species, we performed the oxidation of perfluorinated aromatic substrates bearing electron-withdrawing substituents, namely pentafluorocyanobenzene $\left(\mathrm{C}_{6} \mathrm{~F}_{5} \mathrm{CN}\right)$, pentafluoronitrobenzene $\left(\mathrm{C}_{6} \mathrm{~F}_{5} \mathrm{NO}_{2}\right)$ and octafluorotoluene $\left(\mathrm{C}_{6} \mathrm{~F}_{5} \mathrm{CF}_{3}\right)$ to explore the reaction mechanism for defluorination. Homogeneous catalytic oxidative defluorinations of $\mathrm{C}_{6} \mathrm{~F}_{5} \mathrm{Y}(\mathrm{Y}=$
$\left.\mathrm{CN},-\mathrm{NO}_{2},-\mathrm{CF}_{3}\right)$ substrates $(0.1 \mathrm{M})$ were conducted in $\mathrm{CD}_{3} \mathrm{CN}$, in the presence of $\left(\mathrm{tBu}_{4} \mathrm{PcFe}\right)_{2} \mathrm{~N}(0.4 \mathrm{~mol} \%)$ and $\mathrm{H}_{2} \mathrm{O}_{2}(16$ equiv.) at $60^{\circ} \mathrm{C}$ for 15 hours. Identification and quantification of phenolic products was achieved by ${ }^{19} \mathrm{~F}$ NMR analyses of the reaction mixture after concentration of the reaction mixture using an argon flow (Scheme 2). Detailed procedures for the determination of phenol product ratios are given in the Supporting Information. For all the substrates, a preference for the transformation of the $\mathrm{C}-\mathrm{F}$ bond in the meta-position is observed, which is a normal trend for electrophilic aromatic substitution reactions where the electron withdrawing substituents act as potential meta-directing groups. ${ }^{[12]}$

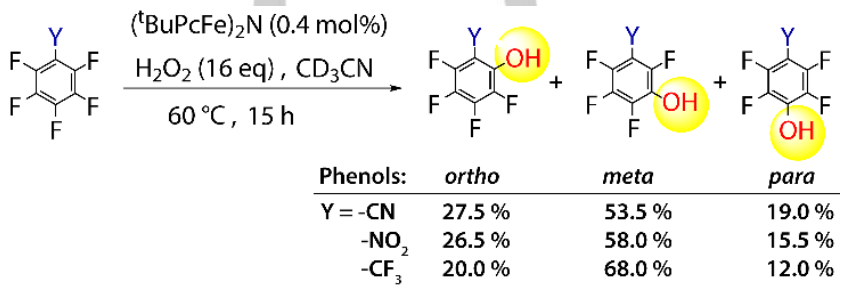

Scheme 2. Ratio of different phenolic products formed as quantified by ${ }^{19} \mathrm{~F}$ NMR analysis.

In order to check the possible effect of the concentration step on the ratio of the produced phenol, we also performed the analyses of the reaction mixtures by GC/MS using two substrates, namely $\mathrm{C}_{6} \mathrm{~F}_{5} \mathrm{CN}$ and $\mathrm{C}_{6} \mathrm{~F}_{5} \mathrm{NO}_{2}$ without the concentration step. The GC/MS analyses were performed after treatment of the reaction mixtures with trimethylsilyldiazomethane to obtain methylated phenol derivatives (Supporting Information, Table S1). The distributions of phenol isomers obtained using the GC/MS method is very similar to those from the ${ }^{19} \mathrm{~F}$ NMR analysis. In particular, for $\mathrm{C}_{6} \mathrm{~F}_{5} \mathrm{CN}$ the two techniques give differences in the ratio of phenols less than $0.3 \%$, hence both methods give quantitatively identical results.

Table 1. Catalytic degradation of $\mathrm{C}_{6} \mathrm{~F}_{6}$ catalysed by $1-\mathrm{H}_{2} \mathrm{O}_{2}$ in $\mathrm{CD}_{3} \mathrm{CN}$ in the presence of various amounts of trifluoroacetic acid (TFA). ${ }^{[\mathrm{a}]}$

\begin{tabular}{llll}
\hline $\begin{array}{l}{[\mathrm{TFA}]} \\
(\mathrm{mM})\end{array}$ & $\begin{array}{l}\text { Conversion } \\
(\%)\end{array}$ & TON $^{[\mathrm{b}]}$ & $\begin{array}{l}\text { Defluorination degree } \\
(\%)^{[\mathrm{c}]}\end{array}$ \\
\hline 0 & 29 & 226 & $52(3.1$ over 6$)$ \\
5 & 36 & 344 & $63(3.8$ over 6$)$ \\
15 & 44 & 412 & $62(3.7$ over 6$)$ \\
70 & 45 & 460 & $68(4.1$ over 6$)$ \\
100 & 49 & 514 & $71(4.2$ over 6$)$ \\
\hline
\end{tabular}

[a] The solution containing the catalyst $(0.4 \mathrm{mM})$, substrate $(0.1 \mathrm{M})$, and $\mathrm{H}_{2} \mathrm{O}_{2}(1.6 \mathrm{M})$ was stirred in $\mathrm{CD}_{3} \mathrm{CN}$ at $60^{\circ} \mathrm{C}$ for $15 \mathrm{~h}$. The substrate conversions and yields of $\mathrm{F}^{-}$were determined by ${ }^{19} \mathrm{~F}$ NMR spectroscopy. [b] Turnovers numbers (TONs) were calculated as the molar amount of $\mathrm{F}^{-}$ formed per mole of catalyst. [c] The degree of defluorination is the ratio of the amount of $\mathrm{F}^{-}$formed to the total amount of fluorine in the converted substrate.

Next, the influence of the presence of acid on the defluorination efficiency was studied. The $1-\mathrm{H}_{2} \mathrm{O}_{2}$ system mediates another 
challenging reaction, namely the mild oxidation of methane in water. $^{[13]}$ The efficiency of the methane oxidation strongly increases upon addition of a small amount of acid and shows a bell-shaped dependence on the acid concentration. ${ }^{[13 \mathrm{~b}]}$ While a turnover number (TON) of 26 was observed in pure water, using a $75 \mathrm{mM} \mathrm{H}_{2} \mathrm{SO}_{4}$ aqueous solution results in the boosting of the turnover number of methane oxidation up to 223. This enhancement can be explained by the more efficient formation of the diiron-oxo species from the hydroperoxo complex due to the protonation of peroxide oxygen leading to easier heterolytic cleavage of the $\mathrm{O}-\mathrm{O}$ bond with release of a water molecule. In line with these previous studies, therefore, we decided to investigate the influence of trifluoroacetic acid (TFA) on the defluorination reaction. In particular, the work focused on the efficiency of defluorination of hexafluorobenzene in the presence of TFA (see Table 1 and Figure 1).

Indeed, upon progressive increase of the TFA concentration from 0 to $100 \mathrm{mM}$, the conversion of $\mathrm{C}_{6} \mathrm{~F}_{6}$ gradually increased from $29 \%$ to $49 \%$ and is accompanied by a more than two-fold increase of turnover number from 226 to 514 (Figure 1). Importantly, the ratio of the amount of $\mathrm{F}^{-}$formed during the reaction to the total amount of fluorine in converted substrate (defluorination degree) was also increased from $52 \%$ to $71 \%$ indicating the higher reaction efficiency in the presence of acid. This enhancement of the reactivity is expected to be correlated to the acceleration of the formation of the $\mathrm{N}$-bridged diiron-oxo species involved in the reaction with fluorinated aromatic substrates, but involvement of protons in the reaction sequence leading to defluorination cannot be excluded (vide infra).

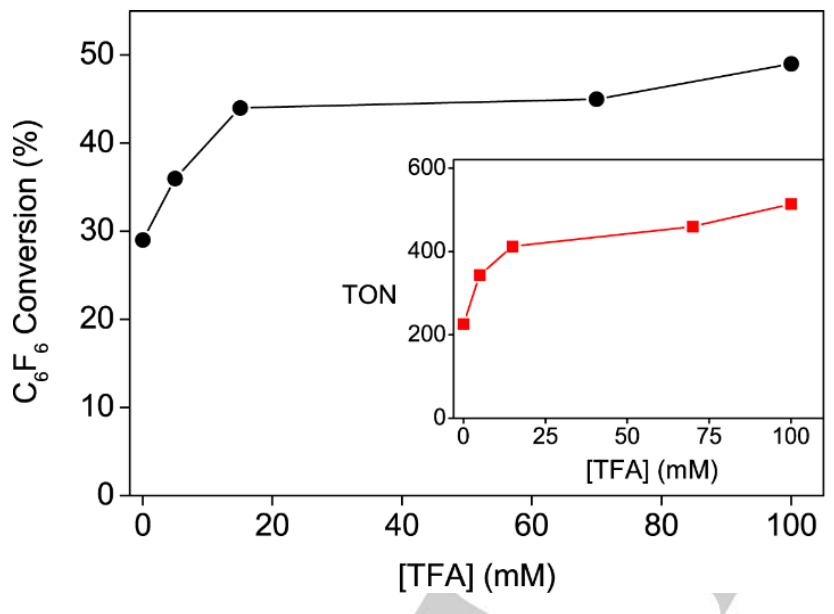

Figure 1. Evolution of the conversion of $\mathrm{C}_{6} \mathrm{~F}_{6}$ catalysed by the $1-\mathrm{H}_{2} \mathrm{O}_{2}$ system as a function of the concentration of TFA. The inset shows the dependence of TON as a function of the TFA concentration.

\section{Mechanistic considerations}

To highlight the mechanistic possibilities of ketone and phenol observation in a reaction of an iron(IV)-oxo intermediate with $\mathrm{C}_{6} \mathrm{~F}_{6}$ we show a possible reaction mechanism of the aromatic hydroxylation in Scheme 3. Thus, computational modelling of the mechanism of aromatic hydroxylation by a P450 Cpd I model, namely an iron(IV)-oxo heme cation radical, showed that the reaction starts with an electrophilic $\mathrm{C}-\mathrm{O}$ bond formation to one of the carbon atoms of the arene, leading to a radical intermediate (Scheme 3$){ }^{[14]}$ Thereafter, a ring-closure step leads to an epoxide or alternatively an ipso-proton abstraction and reshuttle creates either ketone or phenol products. ${ }^{[14]}$ An interconversion between the latter two structures through the socalled $\mathrm{NIH}$-shift with additional protons may be possible as well. As such, acid is involved in some steps of the reaction cycle and the $\mathrm{pH}$ of the reaction mixture should affect product distributions. Importantly, the $1-\mathrm{H}_{2} \mathrm{O}_{2}$ system showed the mechanistic features similar to those of $\mathrm{P} 450 \mathrm{Cpd} \mathrm{I}$ in the oxidation of benzene (intermediate formation of benzene epoxide and $\mathrm{NIH}$ shift evidenced using benzene-1,3,5-[D $\left.\left[\mathrm{D}_{3}\right]\right) .{ }^{[15]}$ Thus, it is likely that the reaction of the perfluoroarene with $\mathrm{N}$-bridged diiron-oxo phthalocyanine will be initiated by a similar electrophilic addition reaction through oxygen atom transfer to the arene. Subsequently, epoxide or ketone products are formed through either a common intermediate or sequentially. These epoxide and ketone products could escape the oxidant environment mixture and into solution. In order to obtain the phenol product, however, one of the fluoride atoms will need to be removed and a proton provided. Hence, this offers a mechanistic challenge with respect to the aromatic hydroxylation mechanism at the top part of Scheme 3, where this proton comes from the original C$\mathrm{H}$ bond that is broken. Thus, oxygen atom transfer to a fluorinated arene to form the epoxide will not need the breaking of a $\mathrm{C}-\mathrm{F}$ bond and as such should be the thermodynamically easiest pathway.

Therefore, based on our experimental work on fluorinated arenes by an iron-oxo species we propose a mechanism whereby an initial epoxide is formed that through an $\mathrm{NIH}$-fluoride shift leads to the ketone prior to fluoride release to form phenol. Alternatively, a fluoride transfer from epoxide to the $\mathrm{N}$-bridged diiron complex can lead to pentafluorophenolate directly. These mechanistic possibilities would make the reactivity of fluorinated arenes different from hydrogenated arenes. Consequently, we decided to pursue a density functional theory study on perfluoroarene activation by $\mathrm{N}$-bridged diiron-oxo phthalocyanine complexes to shed more light on the experimental results.

Thus, the mechanistic possibilities given in the bottom panel of Scheme 3 provide an initial reaction step for hexafluorobenzene epoxidation. The fluoroarene epoxide could rearrange to ketone intermediate through a rare fluorine $\mathrm{NIH}$-shift. This shift was experimentally shown using 1,4-difluorobenzene as a substrate. ${ }^{[10 a]}$ Escape of the ketone intermediate into solution may lead to the loss of $\mathrm{F}^{-}$to generate a cationic species followed by the addition of a hydroxide group to form quinone after elimination of HF. Thus, there is a significant difference in the behavior of the ketone intermediates generated from aromatic hydrocarbons and perfluorinated aromatics. While the former species loses $\mathrm{H}^{+}$to form finally phenol, namely through a 2-electron oxidation reaction, on the other hand, the fluorinated ketone intermediate undergoes fluoride anion elimination leading to direct formation of fluoranil (6-electron oxidation product) without intermediate formation of fluorinated phenol (Scheme 3). However, GC-MS and ${ }^{19} \mathrm{~F}$ NMR analysis unambiguously shows fluorinated phenols as intermediate products. In order to gain insight into how the formation of phenols in the oxidative defluorination of perfluoroarenes could be explained, we decided to do a computational study on the various possible reaction mechanisms. 


\section{P450 reaction cycle of benzene hydroxylation:}

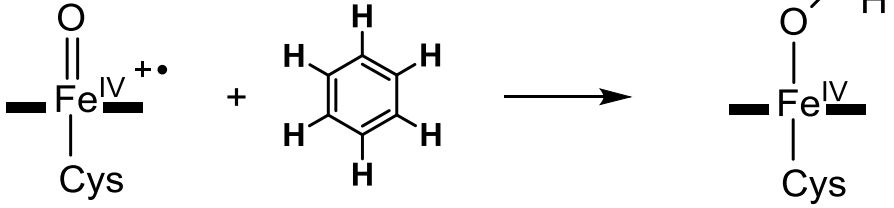<smiles>C[Pb](C)([GeH3])Oc1ccccc1</smiles>

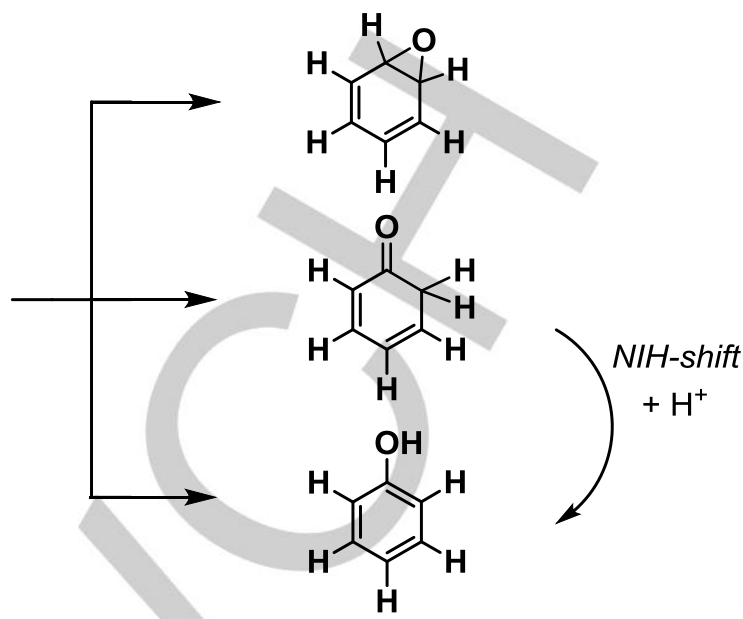

$\mu$-nitrido bridged diiron(IV)-oxo phthalocyanine with $C_{6} F_{6}$ :<smiles>CCN=[P+](C)C</smiles><smiles>Fc1c(F)c(F)c(F)c(F)c1F</smiles><smiles>COC1(F)C(F)=C(F)C(F)=C(F)C1(F)F</smiles><smiles>O=C1C(F)=C(F)C(F)=C(F)C1(F)F</smiles><smiles>C[C+]1C=C[I-](C)C1</smiles><smiles>Oc1c(F)c(F)c(F)c(F)c1F</smiles><smiles>O=C1C(=O)C(F)=C(F)C(F)=C1F</smiles>

Scheme 3. Mechanistic scenarios for the evolution of ketone intermediates from aromatic hydrocarbon and fluorocarbon oxidation by iron(IV)-oxo intermediates: (top panel) P450 Cpd I reaction with benzene. (bottom panel) N-bridged diiron-oxo phthalocyanine reaction with $\mathrm{C}_{6} \mathrm{~F}_{6}$.

An alternative scenario would be that the ketone intermediate is retained by the $\mu$-nitrido diiron-phthalocyanine complex in its coordination sphere. Again, the loss of fluoride anion $\mathrm{F}^{-}$leads to a coordinated cationic species followed by two electron transfer from $\left[(\mathrm{Pc}) \mathrm{Fe}^{\mathrm{III}}-\mu \mathrm{N}-\mathrm{Fe}^{\mathrm{IV}}(\mathrm{Pc})\right]$ to the cationic intermediate. In this way, a high-valent $\mathrm{F}-(\mathrm{Pc}) \mathrm{Fe}^{\mathrm{IV}}-\mu \mathrm{N}-\mathrm{Fe}^{\mathrm{IV}}\left(\mathrm{Pc}^{+\cdot}\right)-\mathrm{F}$ complex will be formed, which was isolated from the reaction mixture and fully characterized by spectroscopic techniques. ${ }^{[10]}$ In turn, reduced fluoroarene residue furnishes phenol, which is obtained as a reaction product. An intramolecular electron transfer and the formation of phenol can be facilitated if the carbonyl group would be protonated. Thus, the presence of acid should be beneficial for the reaction.

\section{Computational modelling of $C_{6} F_{6}$ activation by $\mathrm{N}$-bridged diiron(IV)-oxo}

To gain further insight into the details of the reaction mechanism, and particularly on the order of formation of epoxide, ketone and phenol products, we performed a computational study using density functional theory methods. We started our work with calculations on the iron(IV)-oxo species of $\mathrm{N}$-bridged diironporphyrazine (model A) and $\mathrm{N}$-bridged diiron-phthalocyanine (model B). These structures are found to have a doublet spin ground state in agreement with experimental electron paramagnetic resonance (EPR) and Mössbauer spectroscopic studies. ${ }^{[16]}$ Previous modelling on $\mathrm{N}$-bridged diiron-oxo porphyrins and porphyrazines also found a doublet spin ground state with a singly occupied $\pi$-orbital with molecular orbital coefficients located along the Fe2-N-Fe1-O axis. ${ }^{[11]}$ Several papers by other groups have reported studies on this chemical system and found a similar electronic configuration and structure. ${ }^{[17]}$

For the smallest chemical system $\left({ }^{2} \mathbf{A}\right)$, we calculated three electromers for the doublet spin state (Supporting Information, Figure S8). The most stable configuration for both $\mathbf{A}$ and $\mathbf{B}$ is a doublet spin state structure with an iron(IV)-oxo terminal group, i.e. Fe1-O, with spin densities of 1.1 on Fe1 and 1.0 on $\mathrm{O}$. This is similar to heme and nonheme iron(IV)-oxo species calculated previously that all were shown to have two three-electron bonds along the $\mathrm{Fe}-\mathrm{O}$ axis due to occupation $\pi_{\mathrm{xz}}{ }^{2} \pi^{*}{ }_{\mathrm{xz}}{ }^{1} \pi_{\mathrm{yz}}{ }^{2} \pi^{*}{ }_{\mathrm{yz}}{ }^{1} \cdot{ }^{[16,17]}$ In structures $\mathbf{A}$ and $\mathbf{B}$ these $\pi$ and $\pi^{*}$ orbitals mix further with orbitals on the bridging nitrogen and $\mathrm{Fe} 2$ atoms and, therefore, are more delocalized. 


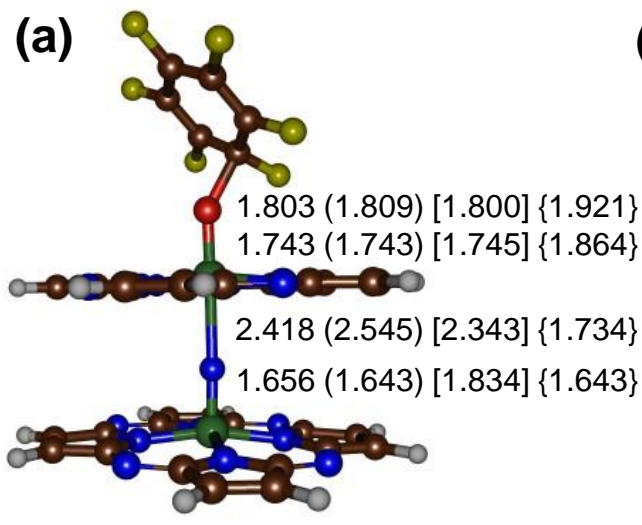

(b)

i815 (i803) [i832] $\{i 601\} \mathrm{cm}^{-1}$

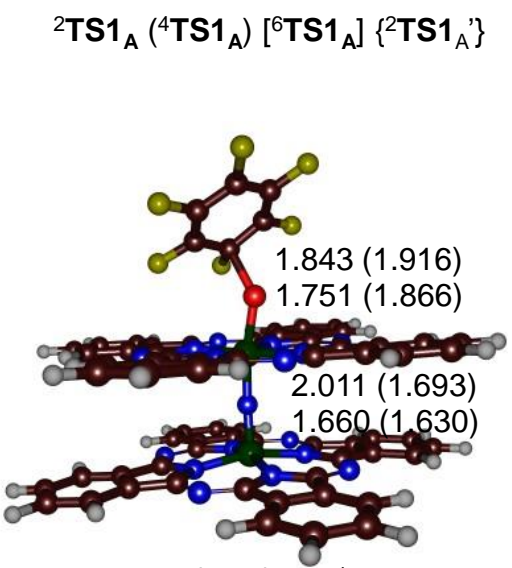

i757 (i595) $\mathrm{cm}^{-1}$

${ }^{2} \mathrm{TS1}_{\mathrm{B}}\left({ }^{2} \mathrm{TS} 1_{\mathrm{B}}\right)$

(b)

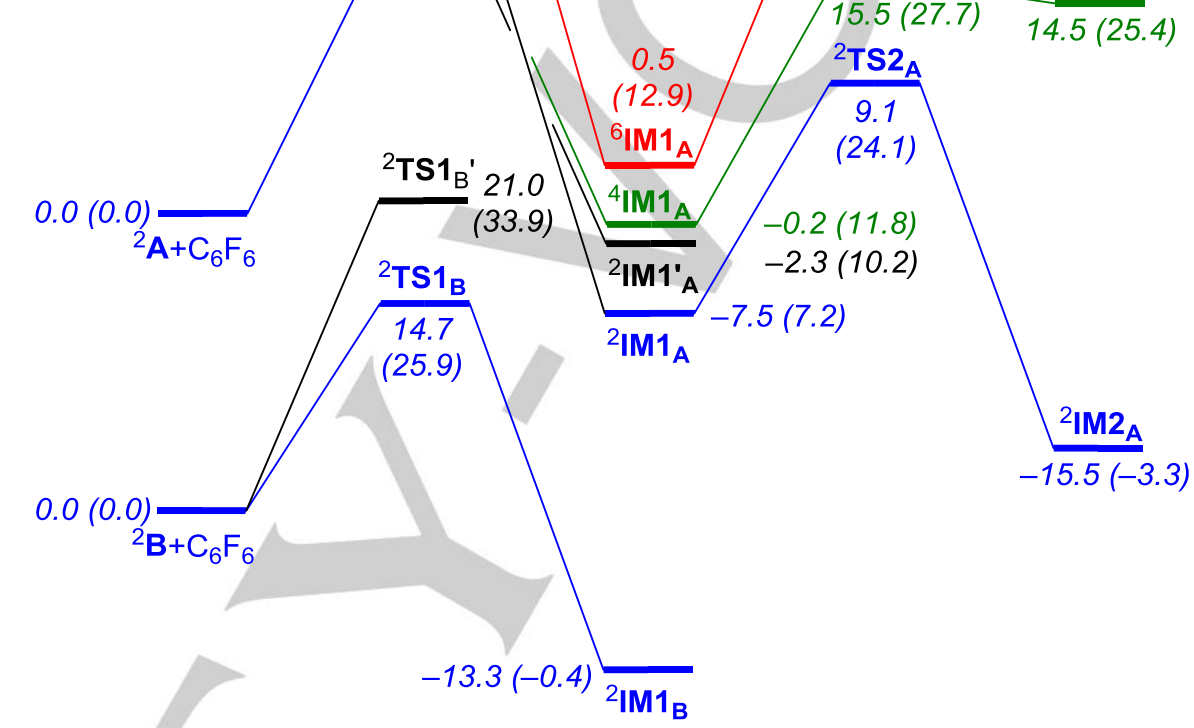

Figure 2. (a) Optimized geometries of electrophilic addition transition states $\mathbf{T S} 1_{\mathrm{A}}$ and $\mathbf{T S} 1_{\mathrm{B}}$ as obtained at UB3LYP/BS1 in Gaussian-09. Bond lengths are given in angstroms and the imaginary frequency in the transition state in $\mathrm{cm}^{-1}$. (b) Potential energy profile for the epoxidation of $\mathrm{C}_{6} \mathrm{~F}_{6}$ by ${ }^{2,4,6}\left[(\mathrm{PzFe})_{2} \mathrm{~N}\right] \mathrm{O}\left({ }^{2} \mathbf{A}\right)$ and ${ }^{2}\left[(\mathrm{PcFe})_{2} \mathrm{~N}\right] \mathrm{O}\left({ }^{2} \mathrm{~B}\right)$ as calculated in Gaussian-09 at UB3LYP/BS1 level of theory. Energies (in kcal mol ${ }^{-1}$ ) reported are UB3LYP/BS2//UB3LYP/BS1 with zero-point and solvent corrections included, while free energies at $298 \mathrm{~K}$ are given in parenthesis.

Thus, in ${ }^{2} \mathbf{A}_{1}$ we find short Fe1-O and Fe2-N distances of 1.648 and $1.662 \AA$ in analogy to previous calculations. Very similar distances are found for the phthalocyanine optimized geometry ${ }^{2} \mathbf{B}_{1}$, where the $\mathrm{Fe} 1-\mathrm{O}$ and $\mathrm{Fe} 2-\mathrm{N}$ distances are 1.649 and $1.678 \AA$, respectively. In addition, the electronic configuration of ${ }^{2} \mathbf{B}_{1}$ resembles that of ${ }^{2} \mathbf{A}_{1}$ (Supporting Information, Figure S8) with group spin densities within a few hundredth of an atomic unit of each other. As such, replacing the phthalocyanine units with porphyrazine has no major structural and electronic effect on the system.

Subsequently, we investigated $\mathbf{C}_{6} \mathrm{~F}_{6}$ activation by ${ }^{2,4,6} \mathbf{A}$ and ${ }^{2} \mathbf{B}$ leading to epoxide products and the results are given in Figure 2. The reaction occurs stepwise with an electrophilic transition state (TS1) leading to a radical intermediate (IM1) followed by a ring-closure transition state (TS2) to form epoxide products (IM2). This mechanism resembles previous computational studies on substrate epoxidation by metal-oxo oxidants. ${ }^{[18]}$ The rate determining reaction step is via the first transition state for both models $\mathbf{A}$ and $\mathbf{B}$. Barriers of $\triangle \mathrm{E}+\mathrm{ZPE}+\mathrm{E}_{\text {solv }}=18.6,18.6$ and $32.6 \mathrm{kcal} \mathrm{mol}^{-1}$ are obtained in the doublet, quartet and sextet spin states, respectively. An alternative doublet spin barrier $\left({ }^{2} \mathbf{T S} 1_{A}{ }^{\prime}\right)$ is about $21.9 \mathrm{kcal} \mathrm{mol}^{-1}$ above reactants. The latter has a distinct electronic configuration and structure from ${ }^{2} \mathbf{T S} \mathbf{1}_{\mathrm{A}}$ (Table S4, Supporting Information) and connects to the radical intermediate ${ }^{2} \mathbf{I M} 1^{\prime} \mathrm{A}$, while ${ }^{2} \mathbf{T S} 1_{\mathrm{A}}$ has a configuration closer to ${ }^{2} \mathbf{I M} \mathbf{1}_{\mathrm{A}}$. Thus, ${ }^{2} \mathbf{I M} \mathbf{1}_{\mathrm{A}}$ has one unpaired electron on the substrate and no spin on the diiron-oxo porphyrazine moiety, whereas ${ }^{2}$ IM1' substrate radical. As such, there are competing pathways on the doublet and quartet spin state surfaces with various possible electronic configurations that are close in energy and most likely the system will react through multistate reactivity patterns on competing barriers. In general, the sextet spin state is high in energy and is not expected to play a major role of importance in the reaction mechanism. Although ${ }^{4} \mathbf{T} \mathbf{S} \mathbf{1}_{\mathrm{A}}$ is low in energy, actually the mechanism beyond ${ }^{4} \mathbf{I} \mathbf{M} \mathbf{1}_{\mathrm{A}}$ is well higher in energy than that on the doublet spin state. Consequently, the main reaction mechanism will take place on the doublet spin state surface, although there are several close-lying doublet spin configurations that still give rise to multistate reactivity patterns. 
<smiles>Fc1c(F)c(F)c(F)c(F)c1F</smiles>

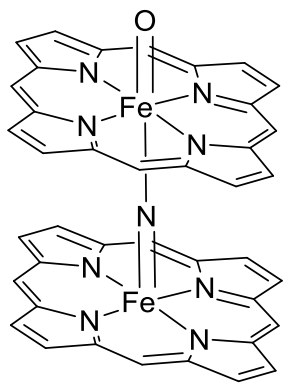

${ }^{2} \mathbf{A} /{ }^{2} \mathbf{B}+\mathrm{C}_{6} \mathrm{~F}_{6}$ 0.0

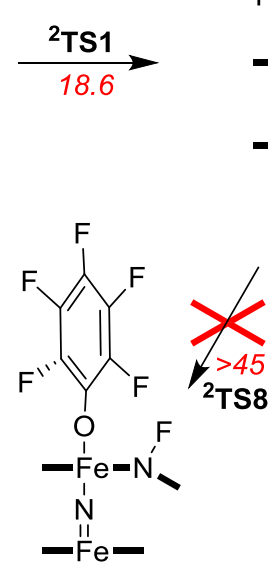

IM5

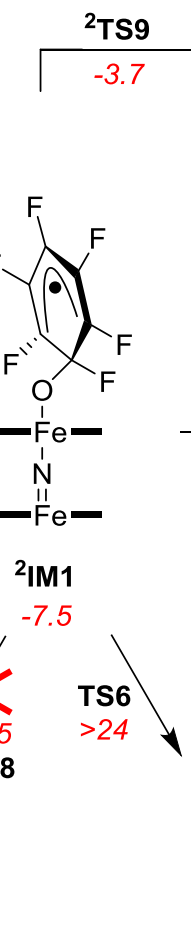

9.1
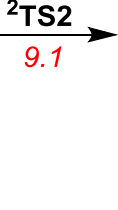
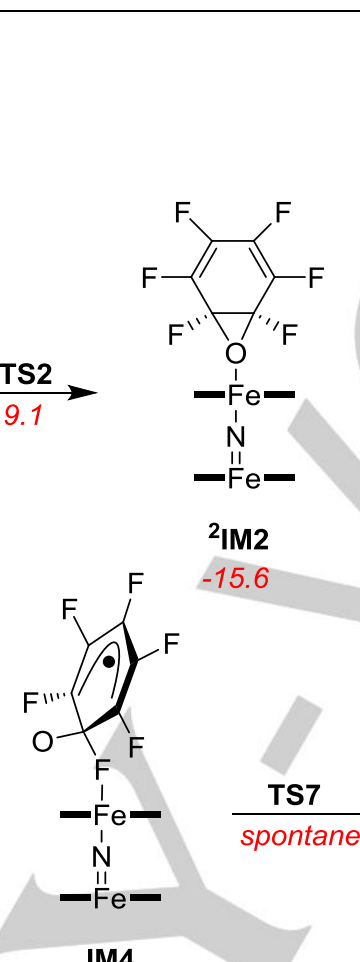<smiles>CP(C)[P+](C)(C)N=C1C(F)=C(F)C(F)=C(F)C1(F)F</smiles>

2IM3

$-39.1$ 2TS4 $-23.3$<smiles>COc1c(F)c(F)c(F)c(F)c1F</smiles>

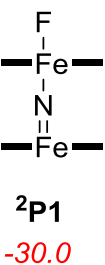

Figure 3. Reaction mechanisms explored for the reaction of $\mathrm{C}_{6} \mathrm{~F}_{6}$ with ${ }^{2}\left[(\mathrm{Pz} F \mathrm{Fe})_{2} \mathrm{~N}\right] \mathrm{O}$, i.e. ${ }^{2} A$ as calculated in Gaussian-09. Energies refer to UB3LYP/BS2//UB3LYP/BS1+ZPE values in $\mathrm{kcal} \mathrm{mol}^{-1}$.

The transition states ${ }^{2} \mathbf{T S} 1_{\mathrm{A}}$ and ${ }^{4} \mathbf{T S} \mathbf{1}_{\mathrm{A}}$ are very similar in structure with a very short Fe2-N distance of 1.656 and $1.643 \AA$, which implicate an $\mathrm{Fe}(\mathrm{IV})$-nitrido bond. By contrast, the Fe1-O distances have elongated from $1.648 \AA$ in the isolated reactant to $1.743 \AA$ in the transition state. Hence, the Fe1-O interaction has weakened. Indeed electron density has accumulated on $\mathrm{Fe} 1$ in ${ }^{2} \mathbf{T S} 1_{\mathrm{A}}$ and a spin density of 2.14 is found. The imaginary frequencies are very high, in the order of $i 800 \mathrm{~cm}^{-1}$, although for ${ }^{2} \mathbf{T S} 1_{\mathrm{A}}$ ' a value of $i 601 \mathrm{~cm}^{-1}$ is calculated. These values are well larger than those typically found for aromatic hydroxylation or epoxidation transition states by iron(IV)-oxo complexes. ${ }^{[14,15,19]}$ On the doublet spin state an alternative transition state was located, namely ${ }^{2} \mathbf{T S} 1_{\mathrm{A}}$ ', which is about $3.3 \mathrm{kcal} \mathrm{mol}^{-1}$ higher in energy than ${ }^{2} \mathbf{T S} 1_{\mathrm{A}}$. Structurally, it has a much shorter Fe1-N distance of $1.734 \AA$ and hence the metal-metal distance is closer This structure also has elongated $\mathrm{Fe} 1-\mathrm{O}$ and $\mathrm{O}-\mathrm{C}$ distances to 1.864 and $1.921 \AA$. As a consequence, the electronic configuration of ${ }^{2} \mathbf{T S} \mathbf{1}_{\mathrm{A}}$ ' is distinct from that of ${ }^{2} \mathbf{T S} \mathbf{1}_{\mathrm{A}}$.

The transition state structures and energies of the larger phthalocyanine model via ${ }^{2} \mathbf{T S} 1_{\mathrm{B}}$ are similar to those seen for the small porphyrazine model A with barriers of 14.7 and $21.0 \mathrm{kcal}$ $\mathrm{mol}^{-1}$ for ${ }^{2} \mathbf{T S} \mathbf{1}_{\mathrm{B}}$ and ${ }^{2} \mathbf{T S} \mathbf{1}_{\mathrm{B}}$. The electronic configuration of ${ }^{2} \mathbf{T S} \mathbf{1}_{\mathrm{A}}$ and ${ }^{2} \mathbf{T S} 1_{B}$ match each other well and so does the pair of ${ }^{2} \mathbf{T S} 1_{A}$, and ${ }^{2} \mathrm{TS} 1_{\mathrm{B}}$ ' structures. Therefore, a change from porphyrazine to phthalocyanine ligand has a small stabilizing effect on the structures and energetics, whereby the barrier is lowered from 18.6 to $14.7 \mathrm{kcal} \mathrm{mol}^{-1}$ but does not affect the overall results.

Electrophilic addition of $\mathrm{C}_{6} \mathrm{~F}_{6}$ to the iron(IV)-oxo species leads to elongation of the Fe-O distance in ${ }^{2,4,6} \mathrm{TS}_{\mathrm{A}}$ to $1.743-1.745 \AA$. These changes are often seen in aromatic hydroxylation reactions calculated previously. ${ }^{[14,20]}$ The group spin densities on $\mathrm{Fe} 2$ and bridging $\mathrm{N}$ are similar to those in the isolated reactant, while the substrate spin increases to -0.26 in ${ }^{2} \mathbf{T S} \mathbf{1}_{\mathrm{A}}$ and 0.94 in 'IM1'A. Therefore, the reaction will not be completely radical in nature and significant charge-transfer will have occurred from the substrate moiety to the metal. The imaginary frequencies are relatively large for $\mathrm{C}-\mathrm{O}$ bond formation transition states and of the order of $i 815 \mathrm{~cm}^{-1}$.

The radical intermediates ( $\mathbf{I} \mathbf{M} \mathbf{1}_{\mathrm{A}}$ and $\mathbf{I} \mathbf{M} \mathbf{1}_{\mathrm{B}}$ ) can lead to epoxide products (IM2 ${ }_{A}$ and $\mathbf{I M 2} \mathbf{B}_{\mathrm{B}}$ ) through a ring-closure step via a transition state TS2. The lowest energy epoxide product is in the doublet spin state and $-15.5 \mathrm{kcal} \mathrm{mol}^{-1}$ below isolated reactants for model A, while the reaction is $-21.8 \mathrm{kcal} \mathrm{mol}^{-1}$ exothermic for model B. The optimized geometries of ${ }^{2} \mathbf{I M} \mathbf{2}_{\mathrm{A}}$ and ${ }^{2} \mathbf{I M} \mathbf{2}_{\mathrm{B}}$ are almost identical with $\mathrm{Fe} 1-\mathrm{N}$ distances of $1.655 \AA$ for both structures and $\mathrm{N}-\mathrm{Fe} 2$ distances of $1.78 \AA$ for both structures. As such they have very similar electronic configuration and properties and hence the equatorial ligand has little effect on the structure and chemical properties of the epoxide product complexes. 
The electrophilic intermediates $\left({ }^{2,4,6} \mathbf{I} \mathbf{M} \mathbf{1}_{\mathrm{A}}\right)$ are on bifurcation pathways that connect to a variety of possible products (Figure 3). Firstly, they can form epoxide products $\left({ }^{2,4,6} \mathbf{I M} \mathbf{2}_{\mathrm{A}}\right)$ via a ringclosure barrier (TS2), Figures 2 and 3. On the doublet spin state surface this barrier is significant; however, and a value of 16.6 kcal mol ${ }^{-1}$ above ${ }^{2} \mathbf{I M} \mathbf{1}_{\mathrm{A}}$ is obtained. Consequently, we searched for lower-energy pathways leading to phenol and ketone products directly. Firstly, ${ }^{2} \mathbf{I M} \mathbf{1}_{\mathrm{A}}$ can react to form the ketone products by a 1,2-fluoride shift and a barrier ${ }^{2} \mathbf{T S} 9_{\mathrm{A}}$ of $3.8 \mathrm{kcal}$ $\mathrm{mol}^{-1}$ higher in energy than ${ }^{2} \mathbf{I} \mathbf{M} \mathbf{1}_{\mathrm{A}}$ was found. The optimized geometry of ${ }^{2} \mathrm{TS}_{\mathrm{A}}$ is given in Figure 4 . Its imaginary mode represents fluoride transfer from the ipso position to its neighboring carbon atom and indeed the intrinsic reaction coordinate scan (Figure S19, Supporting Information) leads to the radical intermediate $\left({ }^{2} \mathbf{I} \mathbf{1}_{\mathrm{A}}\right)$ in one direction and ketone products in the other direction. Long $\mathrm{C}-\mathrm{F}$ bonds of 2.092 and $2.225 \AA$ are obtained in ${ }^{2} \mathrm{TS}_{\mathrm{A}}$ and hence the transition state is close to central.

Next, we looked into alternative reaction pathways for $\mathrm{C}_{6} \mathrm{~F}_{6}$ activation by $\mathrm{N}$-bridged diiron(IV)-oxo complexes leading to phenol products and explored a range of possible mechanisms as shown in Figure 3. Firstly, we tested the $\mathrm{NIH}$-fluoride shift from carbon 1 to carbon 2 in the epoxide structure with ringopening via transition state TS3 to give the ketone product (IM3) We find a small barrier $\left({ }^{2} \mathbf{T S} 3_{\mathrm{A}}\right)$ of $12.2 \mathrm{kcal} \mathrm{mol}^{-1}$ higher in energy than ${ }^{2} \mathbf{I} \mathbf{M} \mathbf{2}_{\mathrm{A}}$ leading in a highly exothermic step to ketone products $\left(-39.1 \mathrm{kcal} \mathrm{mol}^{-1}\right.$ with respect to isolated reactants) ${ }^{2} I M 3_{A}$. Subsequently, one of the aliphatic fluoride atoms of the ketone molecule can be abstracted by the iron atom to form phenol product $(\mathbf{P} \mathbf{1})$ with a barrier $\left({ }^{2} \mathbf{T S} \mathbf{4}_{\mathrm{A}}\right)$ of $15.8 \mathrm{kcal} \mathrm{mol}^{-1}$. Interestingly, formation of phenol from ketone is an endothermic process by $9.1 \mathrm{kcal} \mathrm{mol}^{-1}$. Nevertheless, the activation of $\mathrm{C}_{6} \mathrm{~F}_{6}$ through epoxide and ketone to form phenol has a ratedetermining step for $\mathrm{C}-\mathrm{O}$ bond formation via ${ }^{2} \mathbf{T S} \mathbf{1}_{\mathrm{A}}$ of $18.6 \mathrm{kcal}$ $\mathrm{mol}^{-1}$ and all subsequent barriers are well lower in energy. As such this should be a feasible pathway.

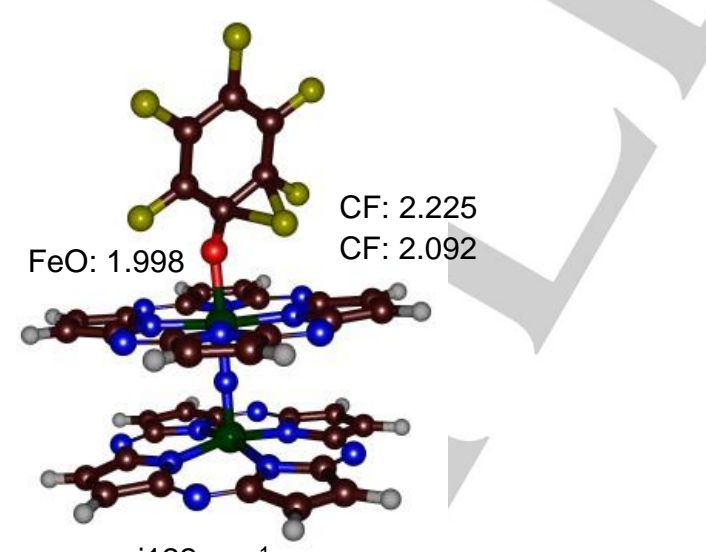

$1122 \mathrm{~cm}^{-1}$

${ }^{2} \mathrm{TS}_{\mathrm{A}}$

Figure 4. UB3LYP/BS1 optimized geometry of ${ }^{2} \mathrm{TS}_{\mathrm{A}}$ with bond lengths in angstroms and the imaginary frequency in the transition state in $\mathrm{cm}^{-1}$.

In addition, several other pathways for oxygen atom transfer to hexafluorobenzene to form pentafluorophenol products were explored (Figure 3). Earlier studies of aromatic hydroxylation of arenes showed the reaction to start with an initial electrophilic addition, like structure IM2 in Figure 3. However, the reaction proceeds through proton-shuttle from the ipso-proton via a nitrogen of the equatorial ligand to the oxygen atom to form phenol. ${ }^{[14,20]}$ A similar mechanism in fluorinated arenes would require an $\mathrm{F}^{-}$transfer to the equatorial ring via TS8 to form intermediate IM5. We estimated the energy for this step from constraint geometry scans (Supporting Information, Figure S20) and predict this pathway to be well higher in energy than $45 \mathrm{kcal}$ $\mathrm{mol}^{-1}$ and hence fluorinated arenes will react through a different mechanism than aromatic hydrocarbons.

A substrate-swing mechanism via transition state TS6 was also explored, where the $\mathrm{Fe}-\mathrm{O}$ bond in the electrophilic intermediate IM1 breaks and is replaced by an Fe-F bond simultaneously to form the radical intermediate IM4. Again, a constraint geometry scan was performed (see Supporting Information, Figure S22). The calculations predict that ${ }^{2} \mathbf{T S} \mathbf{6}_{A}$ is well higher in energy than $24 \mathrm{kcal} \mathrm{mol}^{-1}$ with respect to isolated reactants. This energy is higher than epoxide product formation and, therefore, the substrate-swing mechanism can be ruled out as a viable reaction pathway.

A final pathway investigated was fluoride abstraction from the epoxide product followed by ring-opening to give phenol products. For this pathway, we located transition states for fluoride abstraction $\left({ }^{2} \mathbf{T S} 5_{A}\right)$ and subsequent ring-opening $\left({ }^{2}\right.$ TS5 $\left._{A}{ }_{A}\right)$, see Supporting Information Scheme S4 and Figure S22. Energetically, the energies are very high, namely 29.1 and $34.1 \mathrm{kcal} \mathrm{mol}^{-1}$ above isolated reactants, hence will be inaccessible under room temperature conditions.

In conclusion, the mechanism of oxygen atom transfer to fluorinated arenes has been studied with experimental and computational techniques. It is found to be different to what was established for benzene and its derivatives. Nevertheless, both mechanisms start with an initial electrophilic addition step where a chemical bond between the oxo and one of the carbon atoms of the arene is formed. The latter geometry for a biomimetic mononuclear iron system was characterized by Goldberg and co-workers for a nonheme iron complex. ${ }^{[9 a b]}$ Our calculations show that this intermediate in the $\mathrm{N}$-bridged diironphthalocyanine system will isomerize into a ketone that can lose a fluoride substituent from the aliphatic $\mathrm{C}-\mathrm{F}$ group readily. As such, defluorination is a series reaction where products are formed in a sequential process, while in aromatic hydroxylation of arenes all products appear to arise from a common intermediate. Our mechanism compares favorably to the one proposed for oxygen atom transfer by cytochrome P450 Cpdl to fluorinated arenes. ${ }^{[21]}$ Thus, the mechanism of Hadad and coworkers ${ }^{[21]}$ proceeds with an electrophilic addition followed by $\mathrm{F}^{-}$ migration to form the ketone. As the latter has a low electron affinity they propose a quick $\mathrm{F}$ release to form pentafluorophenol products.

To understand the regioselectivity reactions seen in the experimental studies from Scheme 2, we decided to calculate substrate epoxidation of $\mathrm{C}_{6} \mathrm{~F}_{5} \mathrm{CF}_{3}$ by ${ }^{2} \mathbf{A}$ reactant through an electrophilic attack on either the ortho-, meta- or para-positions. Optimized geometries of ${ }^{2} \mathbf{T S} 1_{\mathrm{A}, \mathrm{CF} 3 \text {,ortho }}$ and ${ }^{2} \mathbf{T S} \mathbf{1}_{\mathrm{A}, \mathrm{CF} 3 \text {,meta }}$ are given in Figure 5. The two structures are very close in energy with the meta-attack configuration slightly lower by $0.7 \mathrm{kcal} \mathrm{mol}^{-1}$. These relative energies imply that a mixture of products leading to ortho- and meta-hydroxylation of $\mathrm{C}_{6} \mathrm{~F}_{5} \mathrm{CF}_{3}$ will be formed with dominant meta-products as indeed observed experimentally. As 
such the calculations on $\mathrm{C}_{6} \mathrm{~F}_{5} \mathrm{CF}_{3}$ predict the correct chemoselectivity as seen experimentally.

Geometrically, the transition states ${ }^{2} \mathbf{T S} 1_{\mathrm{A}, \mathrm{CF} 3 \text {,ortho }}$ and ${ }^{2} \mathrm{TS}_{\mathrm{A}, \mathrm{CF} 3 \text {,meta }}$ are very much alike with $\mathrm{Fe}-\mathrm{O}$ and $\mathrm{C}-\mathrm{O}$ distances of $1.884 / 1.880$ and $1.898 / 1.914 \AA$ for attack on the ortho/meta position of the substrate, respectively. As a consequence of the similarity in transition state geometry also the imaginary frequency in the transition state are close in value, which implies analogous potential energy surfaces for the two processes. In addition, the charge and spin distributions in the two transition states are alike as well with a small positive spin density building up on the substrate $(0.28$ for the ortho and 0.29 for the meta structure) and a radical on the oxo group ( $\rho_{0}=0.72$ for the ortho and 0.70 for the meta structure). The difference in energy between the two transition state structures, therefore, is most likely caused by stereochemical interactions of the $\mathrm{CF}_{3}$ group with the porphyrin/phthalocyanine ligand that raises the ortho pathway slightly in energy.

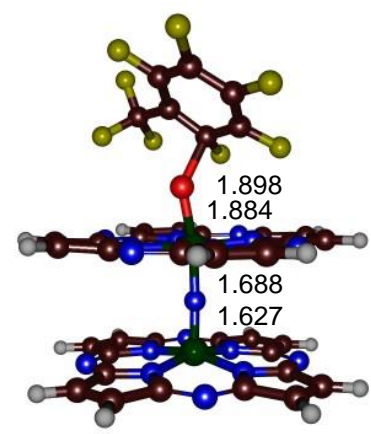

i583 $\mathrm{cm}^{-1}$

${ }^{2} \mathrm{TS1}_{\mathrm{A}, \mathrm{CF} 3 \text {,ortho }}$

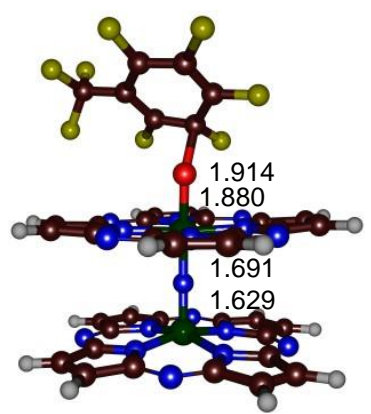

i591 cm-1
Figure 5. UB3LYP/BS1 optimized geometries of ${ }^{2} \mathrm{TS} 1_{\mathrm{A}, \mathrm{CF} 3}$ structures for ortho or meta attack on $\mathrm{C}_{6} \mathrm{~F}_{5} \mathrm{CF}_{3}$ by ${ }^{2} \mathbf{A}$. Bond lengths are in angstroms and the imaginary frequency in the transition state in $\mathrm{cm}^{-1}$.

\section{Discussion}

This work describes the experimental and computational investigation of defluorination of fluoroarenes by a high-valent diiron(IV)-oxo intermediate. Overall, our combined experimental and computational study shows that $\mu$-nitrido bridged diironphthalocyanine complexes are versatile oxidants that can initiate substrate activation of $\mathrm{C}-\mathrm{X}$ bond strengths well over $100 \mathrm{kcal}$ $\mathrm{mol}^{-1}$. As such, these oxidants are more powerful than the active species of most mononuclear metalloenzymes in nature. Furthermore, they are environmentally benign and utilize an iron catalyst with hydrogen peroxide as oxygen donor. In previous work, we and others showed that the iron(IV)-oxo species of the $\mu$-nitrido bridged diiron-phthalocyanine, $\left[(\mathrm{Pc})_{2} \mathrm{Fe}_{2} \mathrm{~N}\right] \mathrm{O}$, efficiently reacts with methane and arenes through oxygen atom transfer to form alcohol products. ${ }^{[11,16]}$ This species is the only known iron(IV)-oxo oxidant to be able to activate methane, whereas in nature a diiron or dicopper complex is typically utilized in the methane monoxygenases. ${ }^{[22]}$

Computational modelling on the properties and reactivities of $\left[(\mathrm{Pc})_{2} \mathrm{Fe}_{2} \mathrm{~N}\right] \mathrm{O}$ showed that orbital interactions along the $\mathrm{Fe}-\mathrm{N}-$ $\mathrm{Fe}-\mathrm{O}$ axis lowered the redox potential of the oxidant and pulled electron density away from the oxo group, thereby affecting the $\mathrm{pK}_{\mathrm{a}}$ of the iron-hydroxo species, which enabled it to hydroxylate methane. ${ }^{[11,16]}$ These studies rationalized the enhanced reactivity of $\mu$-nitrido bridged diiron(IV)-oxo phthalocyanine complexes over mononuclear nonheme and heme iron(IV)-oxo complexes. The work described here shows that the mechanisms of aromatic hydroxylation of arenes and fluoroarenes are distinctively different and in the following we will try to rationalize these differences. Thus, aromatic hydroxylation of arenes (Scheme 3 and 4) typically starts with an aromatic addition of the diron(IV)-oxo species to a carbon atom of the arene. Subsequently, the mechanism bifurcates into the epoxide pathway through a ring-closure step to form epoxide or alternatively an ipso-proton abstraction by the heme to produce a phenolate bound iron(III) complex. The heme proton can thereafter reshuttle to phenolate to either form phenol or ketone products, which explains the experimentally observed $\mathrm{NIH}$-shift. With fluoroarenes the latter mechanism is not feasible as it would have required the removal of an $\mathrm{F}^{+}$ion from the ipsoposition. Indeed, DFT finds a high-energy pathway for $\mathrm{F}^{+}$ abstraction. Therefore, the only feasible pathway for fluoroarene activation by an iron(IV)-oxo species is the formation of an ketone intermediate. Consequently, we find a novel mechanism for the hydroxylation of fluorinated arenes that passes through an electrophilic addition intermediate first and is then converted into a ketone. Only thereafter the phenol is formed through a defluorination step. The initial electrophilic attack of the diiron oxo species at the carbon atom of perfluoroarenes is supported by preferential formation of meta-phenols in course of $\mathrm{C}_{6} \mathrm{~F}_{5} \mathrm{X}$ oxidation (Scheme 2).

The rate-determining step in the reaction mechanism is $\mathrm{C}-\mathrm{O}$ bond formation via ${ }^{2}$ TS1 and to understand the electron transfer mechanisms and the factors that influence this step, we delineated the process in a valence bond diagram (Figure 6). These valence bond diagrams have been used previously to rationalize reaction mechanisms and confirmed trends in, e.g. hydrogen atom abstraction and substrate sulfoxidation reaction by metal-oxo oxidants. ${ }^{[23]}$ Furthermore, these VB diagrams helped to explain regioselectivity patterns and reaction mechanisms by giving details of the electronic configuration and electron migration steps. ${ }^{[24]}$ Thus, the reactant species has a number of $\pi$-type orbitals along the $\mathrm{O}-\mathrm{Fe} 1-\mathrm{N}-\mathrm{Fe} 2$ axis through interactions of the $2 p_{x} / 2 p_{y}$ on O/N with the $3 d_{x z} / 3 d_{y z}$ on Fe1/Fe2. The full set of bonding combinations are the almost degenerate $\pi_{1, x} / \pi_{1, y}$ orbitals that are both doubly occupied. Higher lying are the $\pi_{2, x}$ and $\pi_{2, y}$ orbitals that have a single node and are also doubly occupied. The $\pi_{3, x}$ and $\pi_{3, y}$ orbitals are depicted on the left-hand-side of Figure 6 and are in the valence region and dependent on the spin state and electronic configuration contain one or more electrons. 

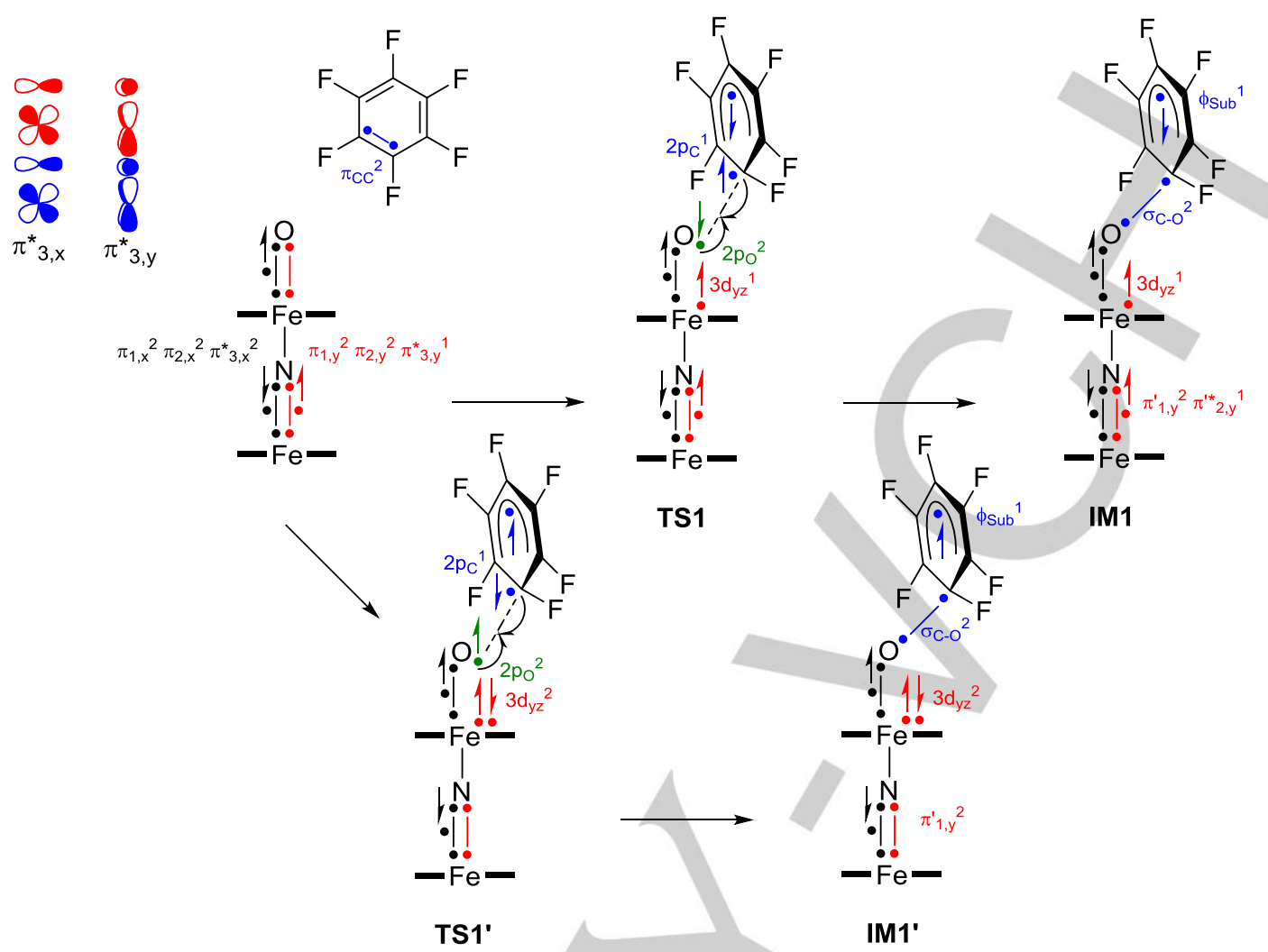

Figure 6. Valence bond description of arene activation step of $\mathrm{C}_{6} \mathrm{~F}_{6}$ by $\mathrm{N}$-bridged diiron-phthalocyanine complexes. Electrons are represented with a dot and a chemical bond as two dots separated by a line. Key orbital occupations during the mechanism are shown.

As shown previously ${ }^{[11]}$ and confirmed for our models here the $\pi_{3, x}$ orbital is doubly occupied and the $\pi_{3, y}$ is singly occupied leading to an overall doublet spin state ground state with orbital configuration $\pi_{1, x}{ }^{2} \pi_{1, y}{ }^{2} \pi_{2, x}{ }^{2} \pi_{2, y}{ }^{2} \pi_{3, x}^{*}{ }^{2} \pi_{3, y}^{*}{ }^{1}$. Two doublet spin transition states and radical intermediates (IM1) were located that have different electronic configuration. Thus, in ${ }^{2} \mathbf{T S} 1 /{ }^{2} \mathbf{I M} \mathbf{1}$ there is positive spin density on the OFeNFe unit and negative spin density on the substrate, whereas in ${ }^{2} \mathbf{T S} 1^{\prime} /{ }^{2} \mathbf{I M} 1$ ' the substrate spin is positive. This implies that there are different electron transfer processes in these pathways, which are explained in Figure 6.

In the C-O bond forming transition states TS1 and TS1' one of the $\pi$-bonds in the arene breaks $\left(\pi_{\mathrm{cc}}\right)$ homolytically. One of those electrons of the arene $\pi_{\mathrm{CC}}$ orbital forms the $\mathrm{C}-\mathrm{O}$ bond with the incoming oxidant, while the other one remains on the substrate in orbital $\phi_{\text {Sub }}$. The $\mathrm{C}-\mathrm{O}$ bond is formed between an electron in a $2 p_{c}$ orbital on the substrate with a $2 p_{\circ}$ orbital on oxygen. The latter comes from the set of $\pi_{y}$ orbitals $\left(\pi_{1, y}, \pi_{2, y}, \pi_{3, y}\right.$, $\left.\pi_{4, y}^{*}\right)$, which split into a new set of orbitals that only covers the Fe1, N and Fe2 atoms: $\pi_{1, y}^{\prime}, \pi_{2, y}^{\prime}$ and $\pi_{3, y}^{* *}$. As such, in ${ }^{2} \mathbf{I M} 1$ a radical intermediate is formed with electronic configuration $3 \mathrm{~d}_{\mathrm{yz}, \mathrm{Fe} 1}{ }^{\uparrow} \pi_{1, \mathrm{yz}, \mathrm{Fe} 2}{ }^{2} \pi_{2, \mathrm{y}, \mathrm{Fe} 2}{ }^{\uparrow} \phi \mathrm{Sub}^{\downarrow}$, with $\phi$ Sub the orbital that hosts the radical on the arene. The alternative mechanism via ' $\mathbf{T S 1}$ ' and 'IM1' by contrast, results in the pairing of a down-spin electron on the carbon atom of the substrate with an up-spin electron in $2 p_{0}$. As a consequence, the $3 d_{x y, F e 1}$ electron is down-spin and the overall spin densities along the $\mathrm{O}-\mathrm{Fe} 1-\mathrm{N}-\mathrm{Fe} 2$ axis virtually cancel out.

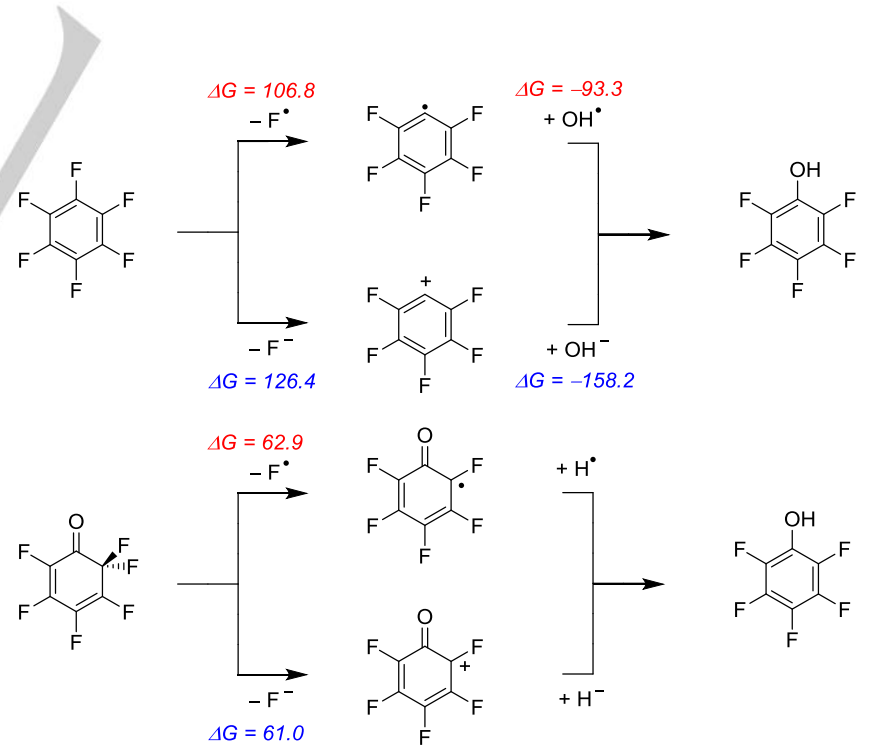

Figure 7. Homolytic (in red) and heterolytic (in blue) $\mathrm{C}-\mathrm{F}$ bond cleavage free energies for $\mathrm{C}_{6} \mathrm{~F}_{6}$ and $\mathrm{C}_{6} \mathrm{~F}_{6} \mathrm{O}$ as calculated at UB3LYP/6-311++ $\mathrm{G}^{* *}$ level of theory. Free energies are in $\mathrm{kcal} \mathrm{mol}^{-1}$ and include thermal (at $298 \mathrm{~K}$ ) and entropic corrections.

To further understand the mechanism of fluoroarene hydroxylation, we did a detailed thermochemical analysis on the individual bonds that are broken and formed in substrate, 
epoxide, ketone and phenol products. Eqs 1 and 2 describe the homolytic ( $\mathrm{Eq} 1$ ) and heterolytic (Eq 2) C-F bond cleavage reactions calculated here. Thus, the homolytic $\mathrm{C}-\mathrm{F}$ bond breaking will produce an $F$ radical with free energy $\Delta G_{\text {nomolytic }}$, while the heterolytic cleavage will give $\mathrm{F}^{-}$anion with free energy $\Delta \mathrm{G}_{\text {neterolytic. }}$

$$
\begin{aligned}
& \mathrm{A}-\mathrm{F} \rightarrow \mathrm{A}^{\cdot}+\mathrm{F}^{\cdot}+\Delta \mathrm{G}_{\text {homolytic }} \\
& \mathrm{A}-\mathrm{F} \rightarrow \mathrm{A}^{+}+\mathrm{F}^{-}+\Delta \mathrm{G}_{\text {heterolytic }}
\end{aligned}
$$

We calculated the adiabatic $\mathrm{C}-\mathrm{F}$ bond cleavage free energy for hexafluorobenzene, hexafluoroarene epoxide and the ketone isomer. Figure 7 and Supporting Information Figures S27 and S28 describe the homolytic and heterolytic free energies of $\mathrm{C}-\mathrm{F}$ bond cleavage of these compounds. As mentioned above, the $\mathrm{C}-\mathrm{F}$ bond is very strong and homolytic and heterolytic $\mathrm{C}-\mathrm{F}$ bond free energies of $\Delta G=106.8$ and $126.4 \mathrm{kcal} \mathrm{mol}^{-1}$ are found, respectively. Similar $\mathrm{C}-\mathrm{F}$ bond strengths are seen for the epoxide complex, which matches the DFT studies above that found high barriers for $\mathrm{C}-\mathrm{F}$ bond breaking in the epoxide complex. However, both heterolytic and homolytic $\mathrm{C}-\mathrm{F}$ bond cleavage from the ketone intermediate is low in energy from the aliphatic $\left(\mathrm{sp}^{3}\right) \mathrm{C}-\mathrm{F}$ bond for which we find adiabatic free energies of 62.9 and $61.0 \mathrm{kcal} \mathrm{mol}^{-1}$, respectively. Therefore, the C-F bond strength in the ketone intermediate is considerably weaker than the aromatic $\mathrm{C}-\mathrm{F}$ bonds in hexafluorobenzene and epoxide isomers. Consequently, the lowest energy hexafluorobenzene hydroxylation will have to pass the ketone intermediate so that the weaker $\mathrm{C}-\mathrm{F}$ bond can be cleaved to form pentafluorophenol products. With release of products from the iron centre, the vacant iron ligand site will be occupied by the fluoride anion. However, as the $\mu$-nitrido bridged diiron-phthalocyanine complex only has two vacant iron sites (on each iron center) it means the complex can only do two turnovers with substrates. To perform catalytic reaction, the formed $\mathrm{F}-(\mathrm{Pc}) \mathrm{Fe}^{\mathrm{IV}}-\mu \mathrm{N}-\mathrm{Fe}^{\mathrm{IV}}\left(\mathrm{Pc}^{+*}\right)-\mathrm{F}$ species should be reduced back to the starting (Pc) $\mathrm{Fe}^{\text {III }}-\mu \mathrm{N}$ $\mathrm{Fe}^{\mathrm{IV}}(\mathrm{Pc})$ complex. We have previously shown that $\mathrm{F}-(\mathrm{Pc}) \mathrm{Fe}^{\mathrm{IV}}$ $\mu \mathrm{N}-\mathrm{Fe}^{\mathrm{IV}}\left(\mathrm{Pc}^{+*}\right)-\mathrm{F}$ reacted with $\mathrm{H}_{2} \mathrm{O}_{2}$ to regenerate $(\mathrm{Pc}) \mathrm{Fe}^{\mathrm{III}}-\mu \mathrm{N}$ $\mathrm{Fe}^{\mathrm{IV}}(\mathrm{Pc})$ for new catalytic cycles. ${ }^{[10 \mathrm{a}]}$

\section{Conclusions}

This work reports a combined experimental and computational study into the defluorination of fluoroarenes by a high-valent diiron(IV)-oxo species. It is shown that the reaction happens with an initial electrophilic addition step to form an epoxide that can rearrange to a ketone form. The latter loses a fluoride to the diiron complex to form phenolate. Overall, defluorination is mechanistically different from aromatic hydroxylation as an aromatic $\mathrm{C}-\mathrm{H}$ versus $\mathrm{C}-\mathrm{F}$ bond is broken. Computational modelling shows that the $\mathrm{C}-\mathrm{F}$ aliphatic bond in the ketone is significantly weaker than the aromatic $\mathrm{C}-\mathrm{F}$ bonds in epoxide and arenes and hence it is essential to pass through the ketone intermediate, which is not needed for aromatic hydroxylation.
Liquid-state ${ }^{1} \mathrm{H}$ and ${ }^{19} \mathrm{~F}$ nuclear magnetic resonance (NMR) spectra were obtained using an AM 250 Bruker spectrometer using a protocol as previously described. ${ }^{[10 a]}$ The UV-vis spectra were recorded with an Agilent 8453 diode-array spectrophotometer. The reaction products were identified by GC-MS technique using a Hewlett Packard 5973/6890 system equipped with an electron impact (EI) ionization source at $70 \mathrm{eV}$. Helium gas was used as the carrier gas and a capillary column with dimensions of $30 \mathrm{~m} \times 0.25 \mathrm{~mm}$ (HP-INNOWax) with poly-ethylene glycol $(0.25 \mu \mathrm{m}$ coating) or DB $5 \mathrm{MS} 50 \mathrm{~m}$ capillary column $(0.250 \mathrm{~mm} \times 0.25$ $\mu \mathrm{m})$ were used. Data were analysed using the NIST Mass Spectral Search Program. ${ }^{[25]}$ The reaction mixtures were prepared for analysis with a preliminary procedure treated with $2.0 \mathrm{M}$ solution of (trimethylsilyl)diazomethane in diethyl ether to convert carboxylic acids to the corresponding methyl esters. The response factors of phenolic products were determined using authentic compounds. When authentic compounds were not available, phenol products were analysed assuming that they have similar response factors as their available isomers.

\section{Theory}

Calculations were performed using density functional theory methods as implemented in the Gaussian-09 software package. ${ }^{[26]}$ In a previous study, ${ }^{[11]}$ we extensively tested several density functional and $a b$ initio methods for the description of the electronic configuration of $\mathrm{N}$-bridged diiron(IV)-oxo complexes and obtained good results against experimental data with the unrestricted B3LYP hybrid density functional method. ${ }^{[27]}$ Therefore, the same procedures were followed in this work.

We initially tested two density functional methods for the electrophilic addition pathway, namely the unrestricted B3LYP and B3LYP-D3 methods. ${ }^{[27,28]}$ Although both methods give similar optimized geometries for the local minima and transition states (see Supporting Information for details), the full mechanism with all possible reaction pathways was done with the UB3LYP method only. These models and methods were extensively benchmarked and calibrated for analogous models and shown to reproduce experimental free energies of activation and spectroscopic parameters well. ${ }^{[29]}$

The geometry optimizations, constraint reaction scans, frequency calculations and intrinsic reaction coordinate scans were done with continuum polarized conductor model included at the UB3LYP level of theory and the LANL2DZ basis set with core potential on iron and 6-31G on the rest of the atoms: basis set $B S 1{ }^{[30]}$ Single point energy calculations were done on the optimized geometries with an LANL2TZ basis set on iron with core potential and $6-311+G^{*}$ on the rest of the atoms: basis set BS2. All calculations were performed with a solvent included through the CPCM model with dielectric constant mimicking acetonitrile. ${ }^{[31]}$

We used two different models, namely model $\mathbf{A}$ and $\mathbf{B}$. Model $\mathbf{A}$ had the two phthalocyanine $(\mathrm{Pc})$ groups abbreviated to porphyrazine $(\mathrm{Pz})$ and all side-chains as hydrogen atoms, whereas model $\mathbf{B}$ represented the full phthalocyanine equatorial ligand without peripheral substituents. These systems were reacted with $\mathrm{C}_{6} \mathrm{~F}_{6}$ as substrate. The full reaction profile was explored for all low-lying doublet, quartet and sextet spin states as identified with a value 2, 4 or 6 in superscript before the label. Transition states were characterized with a single imaginary frequency representing the correct mode, while local minima had real frequencies only. A selection of intrinsic reaction coordinate (IRC) scans was performed on key reaction steps of the mechanism, which confirmed the assigned pathways and connected the transition state to the two local minima.

\section{Experimental Section}

Experiment

\section{Acknowledgements}

SdV and CVS thank the British Council for a UK-India Education Research Initiative (UKIERI) award (DST/INT/UK/P-151/2017). 
ABS is grateful to ANR (France) for supporting this work (grant ANR-16-CE29-0018-01).

Keywords: biomimetic models $\cdot$ reaction mechanism • epoxidation $\cdot$ hydroxylation $\cdot$ enzyme models

[1] a) K. D. Sen, C. K. Jorgensen, Electronegativity, Springer-Verlag, New York, 1987; b) R. J. Kulawiec, R. H. Crabtree, Coord. Chem. Rev. 1990 99, 89-115; c) Synthetic Fluorine Chemistry (Eds.: G. A. Olah, R. D. Chambers, G. K. S. Prakash), Wiley: New York, 1992; d) S. H. Strauss, Chem. Rev. 1993, 93, 927-942.

[2] J. L. Kiplinger, T. G. Richmond, C. E. Osterberg, Chem. Rev. 1994, 94, 373-431.

[3] a) M. Hudlicky, Chemistry of Organic Fluorine Compounds, Macmillan: New York, 1973; b) R. D. Chambers, Fluorine in Organic Chemistry, Wiley: New York, 1973; c) W. A. Sheppard, C. M. Sharts, Organic Fluorine Chemistry, Benjamin: New York, 1969; d) Fluorocarbon and Related Chemistry (Eds.: R. E. Banks, M. G. Barlow), The Chemical Society: London, Vol. I, 1971; e) Fluorocarbon and Related Chemistry (Eds.: R. E. Banks, M. G. Barlow), The Chemical Society: London, Vol. II, 1974; f) B. E. Smart, In The Chemistry of Functional Groups, Supplement (Eds.: D, S. Patai, Z. Rappoport), Wiley: New York, 1983.

[4] a) J. E. Huheey, Inorganic Chemistry: Principles of Structure and Reactivity, $3^{\text {rd }}$ Ed.; Harper and Row: New York, 1983; b) D. M. Lemal, J. Org. Chem. 2004, 69, 1-11.

[5] a) B. E. Smart, In Molecular Structure and Energetics (Eds.: J. F. Liebman, A. Greenberg), VCH Publishers: Deerfield Beach, FL, 1986; Vol. 3, p 141; b) C. Testa, J. Roger, P. Fleurat-Lessard, J.-C. Hierso, Eur. J. Org. Chem. 2019, 233-253; c) T. Fujita, K. Fuchibe, J. Ichikawa, Angew. Chem. Int. Ed. 2019, 58, 390-402; d) O. Eisenstein, J. Milani, R. N. Perutz, Chem. Rev. 2017, 117, 8710-8753; e) T. Ahrens, J. Kohlman, M. Ahrens, T. Braun, Chem. Rev. 2015, 115, 931-972.

[6] a) M. Sono, M. P. Roach, E. D. Coulter, J. H. Dawson, Chem. Rev. 1996, 96, 2841-2888; b) Cytochrome P450: Structure, Mechanism and Biochemistry (Eds.: P. R. Ortiz de Montellano), $3^{\text {rd }}$ Ed., Kluwer Academic/Plenum Publishers, New York, 2005; c) Handbook Of Porphyrin Science (Eds.: K. M. Kadish, K. M. Smith, R. Guilard), World Scientific Publishing Co., New Jersey, 2010; d) T. L. Poulos, Chem. Rev. 2014, 114, 3919-3962; e) X. Huang, J. T. Groves, J. Biol. Inorg. Chem. 2017, 22, 185-207; f) F. P. Guengerich, F. K. Yoshimoto, Chem. Rev. 2018, 118, 6573-6655.

[7] a) B. Meunier, S. P. de Visser, S. Shaik, Chem. Rev. 2004, 104, $3947-$ 3980; b) P. R. Ortiz de Montellano, Chem. Rev. 2010, 110, 932-948.

[8] a) Z. Cong, O. Shoji, C. Kasai, N. Kawakami, H. Sugimoto, Y. Shiro, Y. Watanabe, ACS Catal. 2015, 5, 150-156; b) N. Kawakami, O. Shoji, Y Watanabe, Chem. Sci. 2013, 4, 2344-2348; c) P. Meinhold, M. W. Peters, M. M. Y. Chen, K. Takahashi, F. H. Arnold, ChemBioChem. 2005, 6, 1765-1768.

[9] a) S. Sahu, M. G. Quesne, C. G. Davies, M. Dürr, I. IvanovićBurmazović, M. A. Siegler, G. N. L. Jameson, S. P. de Visser, D. P. Goldberg, J. Am. Chem. Soc. 2014, 136, 13542-13545; b) S. Sahu, B. Zhang, C. J. Pollock, M. Dürr, C. G. Davies, A. M. Confer, I. IvanovićBurmazović, M. A. Siegler, G. N. L. Jameson, C. Krebs, D. P. Goldberg, J. Am. Chem. Soc. 2016, 138, 12791-12802; c) G. de Ruiter, N. B. Thompson, M. K. Takase, T. Agapie, J. Am. Chem. Soc. 2016, 138 1486-1489; d) A. Nova, R. Mas-Ballesté, A. Lledós, Organometallics 2012, 31, 1245-1256.

[10] a) C. Colomban, E. V. Kudrik, P. Afanasiev, A. B. Sorokin, J. Am. Chem. Soc. 2014, 136, 11321-11330; b) C. Colomban, E. V. Kudrik, A. B Sorokin, J. Porph. Phthalocyanines 2017, 21, 345-353; c) P. Afanasiev, A. B. Sorokin, Acc. Chem. Res. 2016, 49, 583-593.

[11] M. G. Quesne, D. Senthilnathan, D. Singh, D. Kumar, P. Maldivi, A. B. Sorokin, S. P. de Visser, ACS Catal. 2016, 6, 2230-2243.

[12] a) P. Sykes, A guidebook to mechanism in organic chemistry. John Wiley \& Sons, Inc., New York, 1961; b) B. M. Smith, March's Advanced Organic Chemistry: Reactions, Mechanisms, and Structure, $7^{\text {th }}$ Edition, John Wiley \& Sons., Inc., Hoboken, New Jersey, 2013.
[13] a) A. B. Sorokin, E. V. Kudrik, D. Bouchu, Chem. Commun. 2008 2562-2564; b) A. B. Sorokin, E. V. Kudrik, L. X. Alvarez, P. Afanasiev J. M. M. Millet, D. Bouchu, Catal. Today 2010, 157, 149-154; c) Ü. Işci, A. S. Faponle, P. Afanasiev, F. Albrieux, V. Briois, V. Ahsen, F. Dumoulin, A. B. Sorokin, S. P. de Visser, Chem. Sci. 2015, 6, 50635075; d) A. B. Sorokin, Chem. Rev. 2013, 113, 8152-8191.

[14] a) S. P. de Visser, S. Shaik, J. Am. Chem. Soc. 2003, 125, 7413-7424; b) D. Kumar, G. N. Sastry, S. P. de Visser, J. Phys. Chem. B 2012, 116, 718-730; c) F. G. Cantú Reinhard, M. A. Sainna, P. Upadhyay, G. A. Balan, D. Kumar, S. Fornarini, M. E. Crestoni, S. P. de Visser, Chem. Eur. J. 2016, 22, 18608-18619.

[15] E. V. Kudrik, A. B. Sorokin, Chem. Eur. J. 2008, 14, 7123-7126.

[16] E. V. Kudrik, P. Afanasiev, L. X. Alvarez, P. Dubourdeaux, M. Clémancey, J.-M. Latour, G. Blondin, D. Bouchu, F. Albrieux, S. E. Nefedov, A. B. Sorokin, Nat. Chem. 2012, 4, 1024-1029.

[17] a) R. Silaghi-Dumitrescu, S. V. Makarov, M.-M. Uta, I. A. Dereven'kov, P. A. Stuzhin, New J. Chem. 2011, 35, 1140-1145; b) M. Ansari, N Vyas, A. Ansari, G. Rajaraman, Dalton Trans. 2015, 44, 15232-15243.

[18] a) C. Linde, B. Åkermark, P.-O. Norrby, M. Svensson, J. Am. Chem Soc. 1999, 121, 5083-5084; b) S. P. de Visser, F. Ogliaro, N. Harris, S. Shaik, J. Am. Chem. Soc. 2001, 123, 3037-3047; c) S. P. de Visser, F. Ogliaro, P. K. Sharma, S. Shaik, J. Am. Chem. Soc. 2002, 124, 1180911826; d) D. Kumar, B. Karamzadeh, G. N. Sastry, S. P. de Visser, J. Am. Chem. Soc. 2010, 132, 7656-7667; e) R. Lonsdale, J. N. Harvey, A. J. Mulholland, J. Phys. Chem. B 2010, 114, 1156-1162; e) D. Kumar, R. Latifi, S. Kumar, E. V. Rybak-Akimova, M. A. Sainna, S. P. de Visser, Inorg. Chem. 2013, 52, 7968-7979; f) A. N. Morozov, D. C. Chatfield, Int. J. Mol. Sci. 2016, 17, 1297.

[19] a) M. T. Green, J. Am. Chem. Soc. 1999, 121, 7939-7940; b) T. Kamachi, K. Yoshizawa, J. Am. Chem. Soc. 2003, 125, 4652-4661; c) S. P. de Visser, S. Shaik, P. K. Sharma, D. Kumar, W. Thiel, J. Am Chem. Soc. 2003, 125, 15779-15788; d) C. M. Bathelt, J. Zurek, A. J. Mulholland, J. N. Harvey, J. Am. Chem. Soc. 2005, 127, 12900-12908; e) J. C. Schöneboom, H. Lin, N. Reuter, W. Thiel, S. Cohen, F. Ogliaro, S. Shaik, J. Am. Chem. Soc. 2002, 124, 8142-8151.

[20] a) S. Shaik, P. Milko, P. Schyman, D. Usharani, H. Chen, J. Chem. Theory Comput. 2011, 7, 327-339; b) S. P. de Visser, Chem. Eur. J. 2006, 12, 8168-8177; c) F. G. Cantú Reinhard, M. A. Sainna, P. Upadhyay, G. A. Balan, D. Kumar, S. Fornarini, M. E. Crestoni, S. P. de Visser, Chem. Eur. J. 2016, 22, 18608-18619.

[21] J. C. Hackett, T. T. Sanan, C. M. Hadad, Biochemistry 2007, 46, 5924 5940.

[22] M. O. Ross, A. C. Rosenzweig, J. Biol. Inorg. Chem. 2017, 22, 307-319.

[23] a) S. Shaik, D. Kumar, S. P. de Visser, J. Am. Chem. Soc. 2008, 130, 10128-10140; b) D. Kumar, G. N. Sastry, S. P. de Visser, Chem. Eur. J. 2011, 17, 6196-6205.

[24] a) A. S. Faponle, M. G. Quesne, S. P. de Visser, Chem. Eur. J. 2016 22, 5478-5483; b) X.-X. Li, V. Postils, W. Sun, A. S. Faponle, M. Solà, Y. Wang, W. Nam, S. P. de Visser, Chem. Eur. J. 2017, 23, 64066418; c) M. A. Kaczmarek, A. Malhotra, G. A. Balan, A. Timmins, S. P. de Visser, Chem. Eur. J. 2018, 24, 5293-5302; d) A. Timmins, M. G Quesne, T. Borowski, S. P. de Visser, ACS Catal. 2018, 8, 8685-8698.

[25] The NIST Mass Spectral Search Program of NIST/EPA/NIH Mass Spectral Library (Version 2; July 23, 2008).

[26] Gaussian 09, Revision D.01, M. J. Frisch, G. W. Trucks, H. B. Schlegel, G. E. Scuseria, M. A. Robb, J. R. Cheeseman, G. Scalmani, V. Barone B. Mennucci, G. A. Petersson, H. Nakatsuji, M. Caricato, X. Li, H. P. Hratchian, A. F. Izmaylov, J. Bloino, G. Zheng, J. L. Sonnenberg, M Hada, M. Ehara, K. Toyota, R. Fukuda, J. Hasegawa, M. Ishida, T. Nakajima, Y. Honda, O. Kitao, H. Nakai, T. Vreven, J. A. Montgomery Jr, J. E. Peralta, F. Ogliaro, M. Bearpark, J. J. Heyd, E. Brothers, K. N Kudin, V. N. Staroverov, R. Kobayashi, J. Normand, K. Raghavachari, A. Rendell, J. C. Burant, S. S. Iyengar, J. Tomasi, M. Cossi, N. Rega, J. M. Millam, M. Klene, J. E. Knox, J. B. Cross, V. Bakken, C. Adamo, J. Jaramillo, R. Gomperts, R. E. Stratmann, O. Yazyev, A. J. Austin, R. Cammi, C. Pomelli, J. W. Ochterski, R. L. Martin, K. Morokuma, V. G. Zakrzewski, G. A. Voth, P. Salvador, J. J. Dannenberg, S. Dapprich, A D. Daniels, Ö. Farkas, J. B. Foresman, J. V. Ortiz, J. Cioslowski, D. J. Fox, Gaussian, Inc., C. T. Wallingford, 2009. 
[27] a) A. D. Becke, J. Chem. Phys. 1993, 98, 5648-5652; b) C. Lee, W. Yang, R. G. Parr, Phys. Rev. B 1988, 37, 785-789.

[28] S. Grimme, J. Antony, S. Ehrlich, H. Krieg, J. Chem. Phys. 2010, 132 154104

[29] a) M. A. Sainna, S. Kumar, D. Kumar, S. Fornarini, M. E. Crestoni, S. P. de Visser, Chem. Sci. 2015, 6, 1516-1529; b) F. G. Cantú Reinhard, A S. Faponle, S. P. de Visser, J. Phys. Chem. A 2016, 120, 9805-9814 c) F. G. Cantú Reinhard, P. Barman, G. Mukherjee, J. Kumar, D
Kumar, D. Kumar, C. V. Sastri, S. P. de Visser, J. Am. Chem. Soc 2017, 139, 18328-18338.

[30] a) P. J. Hay, W. R. Wadt, J. Chem. Phys. 1985, 82, 270-283; b) M. M. Francl, W. J. Pietro, W. J. Hehre, J. S. Binkley, M. S. Gordon, D. J. DeFrees, J. A. Pople, J. Chem. Phys. 1982, 77, 3654-3658.

[31] J. Tomasi, B. Mennucci, R. Cammi, Chem. Rev. 2005, 105, 2999-3093. 


\section{Entry for the Table of Contents}

Layout 2:

\section{FULL PAPER}
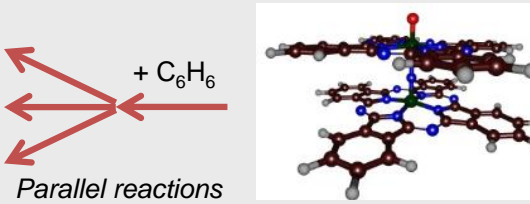

$+\mathrm{C}_{6} \mathrm{~F}_{6}$

Parallel reactions

Cédric Colomban, Anthonio H. Tobing, Gourab Mukherjee, Chivukula V. Sastri, Alexander B. Sorokin, ${ }^{*}$ and Sam P. de Visser*

Page No. - Page No.

A combined experimental and computational study shows that $\mathrm{N}$-bridged diiron phthalocyanine oxidants can react with fluorinated arenes by defluorination reactions. The mechanism is shown to be distinct from typical aromatic hydroxylation reactions and proceeds via a ketone intermediate.

Mechanism of Oxidative Activation of Fluorinated Aromatic Compounds by $\mathrm{N}$-Bridged Diiron-Phthalocyanine. What determines the reactivity? 